\title{
Spectroscopic and Theoretical Studies of Fluorescence Effects in 2-Methylamino-5-(2,4-dihydroxyphenyl)-1,3,4-thiadiazole Induced by Molecular Aggregation
}

\author{
Arkadiusz Matwijczuk ${ }^{1} \cdot$ Andrzej Górecki $^{2} \cdot$ Marcin Makowski $^{3}$. \\ Katarzyna Pustuła ${ }^{3}$ Alicja Skrzypek ${ }^{4}$ Joanna Waś $^{5}$ Andrzej Niewiadomy ${ }^{4,6}$. \\ Mariusz Gagos ${ }^{7}$
}

Received: 2 June 2017 / Accepted: 30 August 2017 / Published online: 9 September 2017

(C) The Author(s) 2017. This article is an open access publication

\begin{abstract}
The article presents the results of fluorescence analyses of 2-methylamino-5-(2,4-dihydroxyphenyl)-1,3,4thiadiazole (MDFT) in an aqueous environment. MDFT dissolved in aqueous solutions with a $\mathrm{pH}$ value in the range from 1 to 4.5 yielded an interesting effect of two clearly separated fluorescence emissions. In turn, a single fluorescence was observed in MDFT dissolved in water solutions with a pH value from 4.5 to 12 . As it was suggested in the previous investigations of other 1,3,4-thiadiazole compounds, these effects may be associated with conformational changes
\end{abstract}

\section{Highlights}

1. The presence of two separate fluorescence emission bands was noted for MDFT at low $\mathrm{pH}$ values.

2. In the interpretation of the results of lifetimes, fluorescence excitation spectra, and RLS, an aggregation model was proposed for the observed phenomenon.

3. Using quantum-mechanical calculations, the role of molecular aggregation on the fluorescence effects was clearly specified.

4. Based on the exciton fission theory, chromophore distances were calculated for molecules forming dimer structures.

5. Based on the crystallographic results, the most optimal model of interactions between the analysed molecules was selected.

Arkadiusz Matwijczuk

arkadiusz.matwijczuk@up.lublin.pl

$\triangle$ Mariusz Gagoś

mariusz.gagos@poczta.umcs.lublin.pl

1 Department of Biophysics, University of Life Sciences in Lublin, Akademicka 13, 20-950 Lublin, Poland

2 Department of Physical Biochemistry, Faculty of Biochemistry, Biophysics and Biotechnology, Jagiellonian University, Gronostajowa 7, 30-387 Krakow, Poland

3 Department of Theoretical Chemistry, Faculty of Chemistry, Jagiellonian University, Ingardena 3, 30-060 Kraków, Poland

4 Department of Chemistry, University of Life Sciences in Lublin, Akademicka 15, 20-950 Lublin, Poland in the structure of the analysed molecule accompanied by aggregation effects. Crystallographic data showed that the effect of the two separated fluorescence emissions occurred in a conformation with the $-\mathrm{OH}$ group in the resorcyl ring bound on the side of the sulphur atom from the 1,3,4-thiadiazole ring. The hypothesis of aggregation as the mechanism involved in the change in the spectral properties at low $\mathrm{pH}$ is supported by the results of (Time-Dependent) Density Functional Theory calculations. The possibility of rapid analysis of conformational changes with the fluorescence spectroscopy technique may be rather important outcome obtained from the spectroscopic studies presented in this article. Additionally, the presented results seem to be highly important as they can be easily observed in solutions and biologically important samples.

Keywords Molecular spectroscopy · 1,3,4-Thiadiazole · Molecular aggregation - DFT calculations - The effect of two fluorescence emission bands

\section{Introduction}

One of the major goals of modern medicine is to address the rapidly increasing problem of cancer diseases. It is estimated that neoplasm diseases will affect one in four inhabitants of highly developed countries in the near future. The

5 Departament of Chemistry, Jagiellonian University, Ingardena 3, 30-060 Kraków, Poland

6 Institute of Industrial Organic Chemistry, Annopol 6, 03-236 Warsaw, Poland

7 Department of Cell Biology, Institute of Biology, Maria Curie-Skłodowska University, Akademicka 19, 20-033 Lublin, Poland 
most important clinical problem associated with the use of chemotherapeutic agents in cancer therapy is the high toxicity of anti tumour drugs which are already available or are being developed. The most effective compounds offering the greatest hope are represented by 1,3,4-thiadiazoles with a substituted resorcyl fragment. The thiadiazol group is a system with comprehensive biological activity $[1,2]$. The activity of 1,3,4-thiadiazoles is related to the presence of a thioimine group in their structure. As indicated in papers by Siddiqui and collaborators [3], this compound group has been investigated worldwide more extensively than all the other thiadiazol isomers. Investigations of 1,3,4-thiadiazole compounds, in particular their di-substituted derivatives, represent a majority in the available literature, probably due to their pharmacological effects. Literature presents the entire thiadiazol family as compounds with anticancer [2, 4-6], antifungal [7], antibacterial [7], anticonvulsant [8], anti-inflammatory [9, 10], antihypertensive [9], antiviral [7], radioprotective [7], antidepressant and antioxidant [11], or insecticidal [9] activity.

Given its confirmed and promising therapeutic activity, 2-methylamino-5-(2,4-dihydroxyphenyl)-1,3,4-thiadiazole (MDFT, Fig. 1a) was chosen for the investigations of the mechanism of molecular interactions presented in this paper [10]. Additionally, the 1,3,4-thiadiazol compounds chosen for the study exhibit very interesting effects related to their pharmacological and spectroscopic applications, e.g. the effects of keto/enol tautomerism induced by changes in environment polarizability [12-15], crystal polymorphism effects [16], solvatomorphism [17], and the very interesting interactions in model lipid systems $[18,19]$. The selected test compounds of group 1,3,4-thiadiazols are also very interesting group of ligands, forming complexes with metal ions block d [20]. The presented 1,3,4-thiadiazols mainly exhibit interesting dual fluorescence [21-23] or two separate emissions, but the mechanism of these effects have not been fully recognised and elucidated despite the extensive research. The combination of the spectroscopic and structural effects presented in the aforementioned papers is extremely important for elucidation of the pharmacological phenomenon of the analysed 1,3,4-thiadiazols.

The main aim of this study was to provide spectroscopic analyses of the molecular organisation of MDFT in an water medium at different concentrations of hydrogen ions and temperature fluctuations. With the use of spectroscopic methods, e.g. electronic absorption spectroscopy, fluorescence technique with RLS, and measurements of fluorescence lifetimes, the complexity of the physical processes involved in the MDFT fluorescence effects induced by changes in the hydrogen ion concentration was demonstrated. Based on the fluorescence measurements and the accessibility X-ray crystallography data, an attempt at experimental and theoretical elucidation of these effects

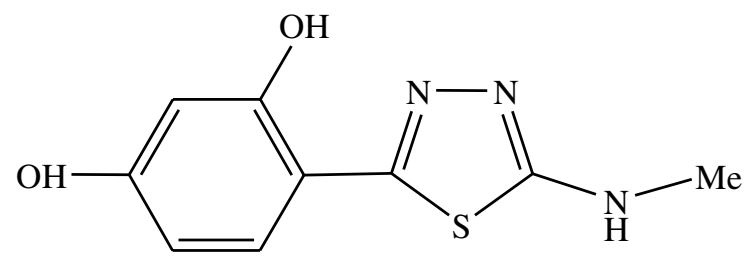

a

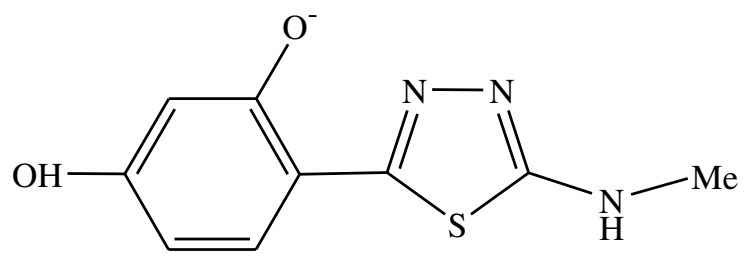

b

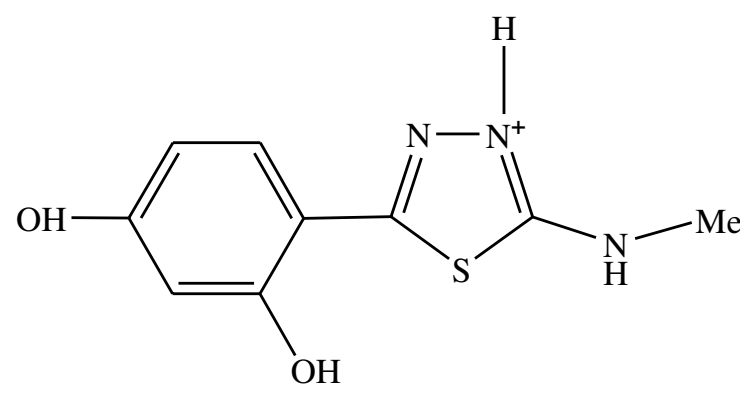

C

Fig. 1 Chemical structure of the MDFT molecule (a enol form, b form ionised with the $-\mathrm{O}^{-}$group, c form ionised with the- $\mathrm{N}^{+}-\mathrm{H}$ group, in which the- $\mathrm{OH}$ group is located on the side of sulphur from the 1,3,4-thiadiazole ring)

were made. As indicated by the crystallographic studies, the rotation of the resorcyl fragment of the molecule and the site of hydrogen atom protonation, depending on the $\mathrm{pH}$ of the environment of crystal growth, yield the fluorescence effects which were mentioned above.

The effects associated with dual fluorescence [24-33] or two clearly shifted fluorescence emissions are related to emergence of two distinctly separated emission spectra induced by electronic excitation. They are usually associated with the solvent polarity, $\mathrm{pH}$ of the environment, temperature, and molecular aggregation. The most common attempts at elucidation of these effects take into account processes connected with the appearance of intra molecular CT states [34-39] or CT states with TICT (Twisted Intramolecular Charge Transfer) [40-50]. Another equally interesting and very popular explanation of the phenomena mentioned above is the Excited-State Intra molecular Proton Transfer (ESIPT) process [25, 51-56]. Such effects are usually observed in organic molecules in which the acceptor group is located close to the proton-donor group. Similar effects can also be explained by the existence of excimer fluorescence [57-64]. In addition, it is worth to mention announced by Brancato and associates a result "anti - Kasha", by which we are also seeing the effect of dual fluorescence [65]. 
The fluorescence spectroscopy analyses of MDFT in a aqueous environment revealed an effect of two distinctly separated and largely overlapping fluorescence emissions. This effect can be induced by the hydrogen ion concentration, temperature fluctuations, solvent polarity, and aggregation effects. Detailed analysis of the organisation of the investigated molecules in an aqueous environment is important for understanding the pharmacological applications of 1,3,4-thiadiazoles.

\section{Materials and Methods}

\section{Materials}

The 2-methylamino-5-(2,4-dihydroxyphenyl)-1,3,4-thiadiazole (MDFT) compound (see Fig. 1) was synthesized in the Department of Chemistry of the University of Life Sciences in Lublin; details of the procedure are described elsewhere [10].

The purification procedure of the MDFT compound is described in detail in references $[16,17,66]$.

\section{Methods}

All solutions were measured with an Elmetron CP-502 pHmeter at room temperature. For methanol-MDFT solutions, MDFT was first dissolved in methanol and the $\mathrm{pH}$ was changed by slow addition of $0.1 \mathrm{M} \mathrm{HCl}$ to the glass flask. For waterMDFT solutions, $0.1 \mathrm{M} \mathrm{NaOH}$ was first added to water to obtain $\mathrm{pH}$ 12. Next, powdered MDFT was dissolved in water. To obtain the specified $\mathrm{pH}$ of the water-MDFT solution, $0.1 \mathrm{M}$ $\mathrm{HCl}$ was slowly added. The $\mathrm{pH}$ was continually controlled.

\section{Electronic Absorption and Fluorescence Spectra}

Electronic absorption spectra of MDFT were recorded on a double-beam UV-Vis spectrophotometer Cary 300 Bio (Varian) equipped with a thermostatted tray holder with a $6 \times 6$ multi-cell Peltier block. The temperature was controlled with a thermocouple probe (Cary Series II from Varian) placed directly in the sample.

Fluorescence excitation, emission, and synchronous spectra were recorded with a Cary Eclipse spectrofluorometer (Varian) at $22^{\circ} \mathrm{C}$. Fluorescence spectra were recorded with $0.5 \mathrm{~nm}$ resolution and corrected for the lamp and photomultiplier spectral characteristics. Resonance light scattering (RLS) measurements were performed as shown in Pasternack and Collings [67]. The excitation and emission monochromators of the spectrofluorimeter were scanned synchronously $(0.0 \mathrm{~nm}$ interval between excitation and emission wavelengths); the slits were set to obtain spectral resolution of $1.5 \mathrm{~nm}$. The spectral analysis was performed with the use of Grams/AI 8.0 software (Thermo Electron Corporation).

\section{Time-Correlated Single Photon Counting (TCSPC)}

Time-correlated single photon counting (TCSPC) measurements were performed using a FluoroCube fluorimeter (Horiba, France). The samples were excited with pulsed NanoLED diode at $372 \mathrm{~nm}$ (pulse duration of $150 \mathrm{ps)} \mathrm{operated}$ with $1 \mathrm{MHz}$ repetition. To avoid pulse pile-up, the power of the pulses was adjusted to an appropriate level using a neutral gradient filter. Fluorescence emission was recorded using a picosecond detector TBX-04 (IBH, JobinYvon, UK). The Data Station and DAS6 software (JobinYvon (IBH, UK)) were used for data acquisition and signal analysis. All fluorescence decays were measured in a $10 \times 10 \mathrm{~mm}$ quartz tray using an emitter bandpass filter with a centre wavelength of 420 and $40 \mathrm{~nm}$ bandwidth. The excitation profiles required for the simplified analysis were measured without the emitter filters on a light scattering tray. All measurements were performed in water at $20^{\circ} \mathrm{C}$ and various $\mathrm{pH}$ values. Each case of fluorescence decay was analysed with a multi-exponential model shown in the equation:

$I_{t}=\sum_{i} \alpha_{i} \exp \left(-t / \tau_{i}\right)$

where $\alpha_{\mathrm{i}}$ and $\tau_{\mathrm{i}}$ are the pre-exponential factor and the decay time of component $i$, respectively.

The best-fitted parameters were obtained by minimization of the reduced $\chi^{2}$ value as well as residual distribution of the experimental data. The fractional contribution $\left(f_{i}\right)$ of each decay time and the average lifetime of fluorescence decay $(<\tau>)$ were calculated with the following equations:

$f_{i}=\frac{\alpha_{i} \tau_{i}}{\sum_{j} \alpha_{j} \tau_{j}}$

$\langle\tau\rangle=\sum_{i} f_{i} \tau_{i}$

\section{DFT Calculations}

The DFT calculations were performed with the Gaussian 09 package [68] using B3LYP exchange-correlation functional [69] and 6-31G** basis set [70]. The dispersion effects were accounted for in the framework of Grimme's D3 model augmented by the Becke-Johnson damping scheme [71]. The solvent effects were modelled by PCM formalism [72]. The excited state treatment was carried out using a standard RPA approach to TD DFT formalism [73] while the influence of the solvent on energetics was determined according to the linear response approximation. 


\section{Results and Discussion}

\section{Spectroscopic Studies of the MDFT Fluorescence Effects in Aqueous Solutions}

Analyses of the MDFT performed in the aqueous solution over the entire $\mathrm{pH}$ range indicate distinct changes in the positions of absorption bands, especially in the region that is important for physiological values. Figure $2 \mathrm{a}$ presents the electron absorption spectra of MDFT obtained at various $\mathrm{pH}$ values ( $\mathrm{pH} 1,7,8,10$, and 12 , respectively). Dissociation of the $-\mathrm{OH}$ group of the resorcyl ring in the orto position (Fig. 1b) causes a hypsochromic spectral shift (by $2949 \mathrm{~cm}^{-1}$ ) in the case of the MDFT spectrum at $\mathrm{pH} 12$ and a bathochromic shift (by $586 \mathrm{~cm}^{-1}$ ) for the spectrum at $\mathrm{pH}$ 7. The ionisation process can also be accompanied by processes of compound aggregation [74]. The increase in the MDFT absorption bandwidth at $\mathrm{pH}$ 7.5-8 suggests possible presence of other than monomeric spectral forms of the compound [75]. The compound absorbance for the spectrum at $\mathrm{pH} 2$ has the lowest value, which indicates predominance of the aggregated forms. Unexpectedly, in the case of the MDFT spectrum at $\mathrm{pH} 1$, absorbance significantly increased, which may suggest processes associated with monomerisation of the compound. Panel b in Fig. 2 shows the ratio of the maximum absorbance at $353 \mathrm{~nm}$ (predominant monomeric form) to that at $317 \mathrm{~nm}$ (predominant associated form), depending on the $\mathrm{pH}$ of the aqueous solution. As can be seen, the MDFT monomerisation level (i.e. the predominance of the monomeric form) is the highest at $\mathrm{pH} 12$ and exhibits a minimum value at $\mathrm{pH} 1$. The greatest changes in the presented ratio are especially evident at $\mathrm{pH} 6-8$, which is associated with the $\mathrm{pK}$ point associated with protonation of the nitrogen atom (located closer to the NH group in the substituent group) from the 1,3,4-thiadiazol ring.
The fluorescence spectroscopy measurements were carried out in the subsequent stage of the study of the spectroscopic properties of MDFT. Together with the change in the $\mathrm{pH}$ of the solution, there was a single fluorescence effect or two, clearly separated, partially overlapping emission spectra. Given the analogy to crystals growing in an acidic environment and suggesting a molecule conformation associated with the observed effect, analyses in aqueous solutions were performed for better elucidation of the effect demonstrated by MDFT. In Fig. 3, the effect of two clearly separated and overlapping fluorescence emissions can be observed in the $\mathrm{pH}$ range of 1-3.5 and single fluorescence is visible for $\mathrm{pH} 4-12$. In the other polar and non-polar solvents, only single fluorescence is visible (not shown). Figure 3 presents selected spectra of MDFT fluorescence emission obtained at different $\mathrm{pH}$ values in the aqueous solution (pH 1, 4, and 6, respectively). The excitation wavelength for all the analysed samples was $323 \mathrm{~nm}$ at $\mathrm{pH} 6,320 \mathrm{~nm}$ at $\mathrm{pH} 4$, and $316 \mathrm{~nm}$ and $360 \mathrm{~nm}$ at $\mathrm{pH} 1$. As shown, single fluorescence with a maximum at ca. $400 \mathrm{~nm}$ (for both excitations) can be observed at $\mathrm{pH} 6$ (and up to $\mathrm{pH} 12$ ). At $\mathrm{pH} 4$, an increase in the bandwidth and a slight bathochromic shift of the emission spectrum are visible. Next, the decrease in the $\mathrm{pH}$ values (between $\mathrm{pH} 3.5$ and 1) is accompanied by additional fluorescence with a maximum at $450 \mathrm{~nm}$ at an excitation wavelength of $360 \mathrm{~nm}$. Moreover, unlike in the case of the dissolved MDFT spectra, a ca. 100-nm shortwave shift of the emission spectra is observed in the solid form (not shown) [21]. This effect can be attributed to the denser arrangement of MDFT molecules in the crystal than in the environment of various solutions. Additionally, in the case of the fluorescence emission spectra for excitation with a 360-nm wavelength, a significant increase in the bandwidth and a decrease in the band intensity can clearly be seen. The inset in Fig. 3 presents the structure of the MDFT molecule crystallized in $\mathrm{H}_{2} \mathrm{O}$ [66]. Furthermore, it can be

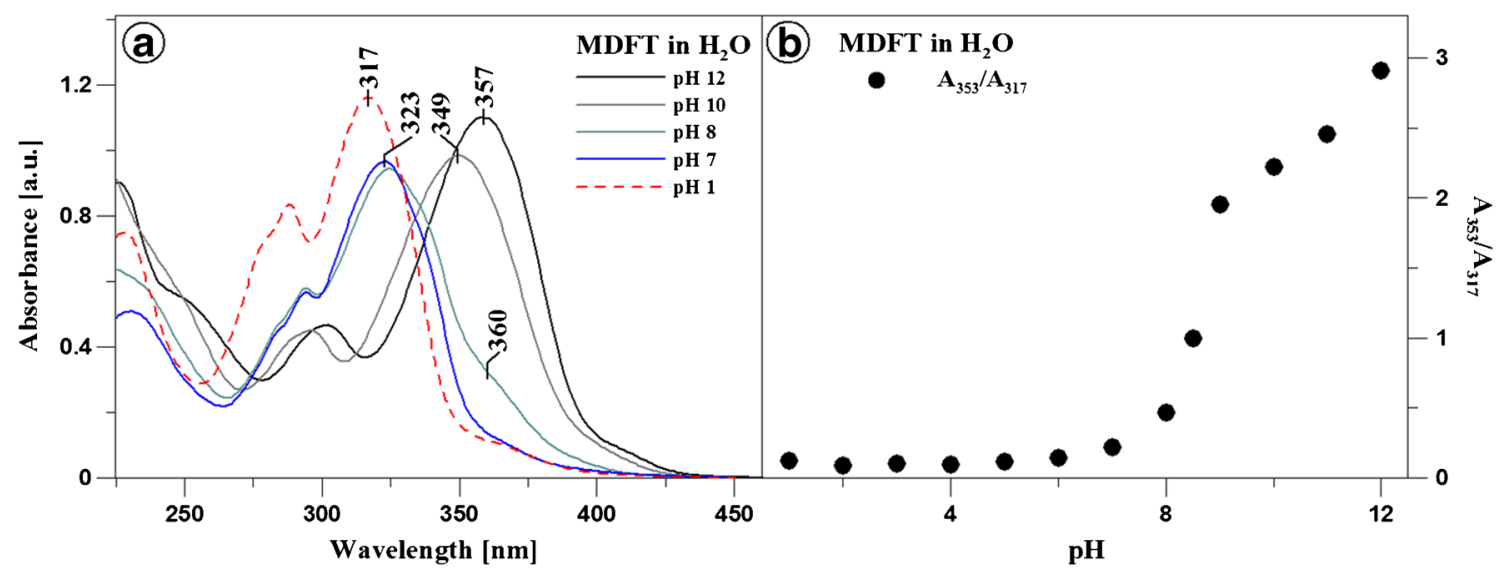

Fig. 2 MDFT electron absorption spectra obtained in the aqueous solution at $\mathrm{pH} 12,10,8,7,1$ (Panel a). Panel $\mathbf{b}$ in the inset presents the ratio of the 353 to 317 absorption maximum depending on the changes of the $\mathrm{pH}$ of the environment 


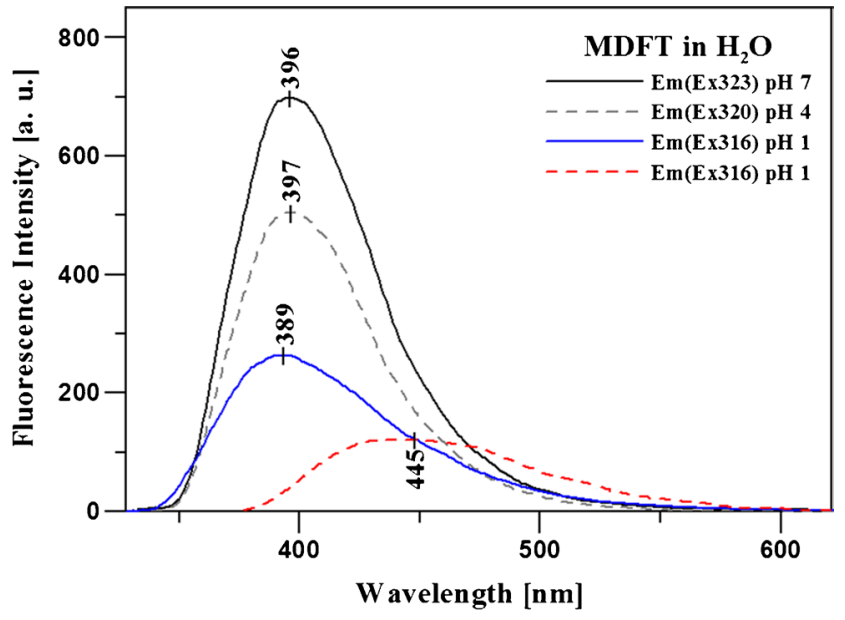

Fig. 3 MDFT fluorescence emission spectra obtained in the aqueous solution at various $\mathrm{pH}$ values ( $\mathrm{pH} 1,4$, and 7 , respectively). The Em(Ex323) symbol denotes emission at an excitation wavelength of $323 \mathrm{~nm}$

noted that the ratio of the MDFT fluorescence maxima over a wavelength range from 396 to $450 \mathrm{~nm}$ depending on the $\mathrm{pH}$ of the solutions changing from $\mathrm{pH} 1$ to $\mathrm{pH} 3.5$ almost does not change. This implies that the process of protonation of the nitrogen atom in the heterocyclic ring (Fig. 1) is in equilibrium with the enol form of the compound and does not change the ratio. Above $\mathrm{pH} 3.5$, the ratio increases substantially and the fluorescence with a maximum at ca. $450 \mathrm{~nm}$ almost disappears.

Figure 4 shows electron absorption spectra for MDFT in the aqueous solution with $\mathrm{pH} 6$ (black line) and in the same solution acidified with $0,1 \mathrm{M} \mathrm{HCl}$ to $\mathrm{pH} 1$ (red line). Both spectra were normalised at a maximum wavelength for easier interpretation. As can be noted, there are evident concurrent bathochromic and hypsochromic shifts. For MDFT dissolved in the aqueous solution, a bathochromic shift from $323 \mathrm{~nm}\left(30,960 \mathrm{~cm}^{-1}\right)$ at $\mathrm{pH} 7$ to $360 \mathrm{~nm}$ $\left(27,778 \mathrm{~cm}^{-1}\right)$ at $\mathrm{pH} 1$ and a hypsochromic shift to $317 \mathrm{~nm}$ $\left(31,546 \mathrm{~cm}^{-1}\right)$ at $\mathrm{pH} 1$ are visible $(\Delta \nu$ between $323 \mathrm{~nm}$ and $360 \mathrm{~nm}$ is $3182 \mathrm{~cm}^{-1}$ ). This characteristic effect involves molecular aggregation processes [76]. The Resonance Light Scattering RLS technique (described below) and DFT quantum-mechanical calculations (described below) most probably indicate MDFT chromophore aggregation effects [21]. Based on the exciton splitting theory and the spectral shifts, it was possible to calculate the distance between the adjacent chromophores of the MDFT molecules [67]. The distance between the adjacent chromophores $\mathrm{R}_{\beta}$ can be calculated from equation:

$R_{\beta}=1.71 \sqrt[3]{\frac{\mu^{2} \kappa}{\eta^{2} \beta}}$

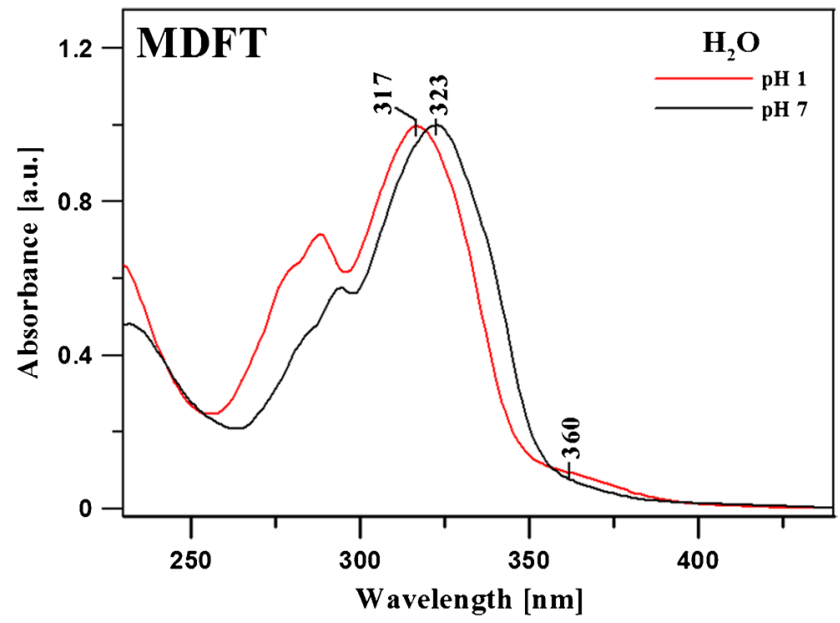

Fig. 4 Normalised MDFT electron absorption spectra obtained in the aqueous solution at $\mathrm{pH} 7$ and 1 (red line and black dashed line, respectively)

where $\mu$ is the transition dipole moment of interacting molecules, $\eta$ - refractive index, $\beta$ - energy of the dipole-dipole interaction (calculated in a classical way). The exciton model takes into account an aggregated structure, formed by identical particles, in which transition dipole moments of adjacent molecules are parallel; hence, $\alpha=0$ (where $\kappa=1-3 \cos ^{2} \theta$, where $\theta$ is an angle between the transition dipole moments of the neighbouring molecules). $\kappa=1$ for the card pack molecule aggregates and $\kappa=-2$ for the head to tail molecular aggregation type. The transition dipole moment for the MDFT monomer calculated by integration of the absorption spectrum has a value of $\mu=4.6 \mathrm{D}\left(\right.$ in $\left.\mathrm{H}_{2} \mathrm{O}\right)$. In the case of MDFT dimers in the aqueous solution, the distance between the adjacent chromophores is estimated at $3.77 \AA$ [67]. These results are consistent with crystallographic data, where the distance between adjacent molecules in the crystal growing in an aqueous solution was $3.35 \AA$ [66]. This distance in crystals is obviously smaller than that calculated for the solutions due to the evidently denser arrangement of crystal molecules and the enhanced strength of inter-molecular interactions.

\section{TCSCP Study}

Figures 5 and 6 as well as Table 1 present the results of measurements of fluorescence lifetimes for MDFT in the aqueous solution over the entire $\mathrm{pH}$ range (shown for 1,7 , 8 , and 12). The excitation wavelength $(372 \mathrm{~nm})$ is appropriate for the long-wave edge of absorption of the monomeric form and the resonant excitation of the aggregated form $(\sim 370 \mathrm{~nm})$ at $\mathrm{pH}$ 7. In turn, at a high $\mathrm{pH}$ level, ionised MDFT forms, i.e. monomers, are excited (see Fig. 4), and aggregates are resonance-excited at low $\mathrm{pH}$ values. The 
fluorescence decay was monitored with the TCSPC method at $22{ }^{\circ} \mathrm{C}$ for a wavelength light range of $400-440 \mathrm{~nm}$. The results were analysed by deconvolution of the fluorescence decay with the use of the apparatus profile and Eq. (1), each time for $i=1,2$, and 3. The two-exponential fluorescence decay model was optimal in all the cases. The mono-exponential decay was insufficient, and the inclusion of the third component did not improve the quality of the fit, which was verified by the value of the fit parameter and the residue distribution analysis (Fig. 5b). Both fluorescence lifetime components exhibit low variation over the entire $\mathrm{pH}$ range, see Fig. 6a. The shorter one, on average $0,13 \pm 0,07 \mathrm{~ns}$, can be considered constant over the analysed range. The fluorescence lifetime for the second component is $2.19 \pm 0.04 \mathrm{~ns}$ for $\mathrm{pH}$ values higher than 5 . For the more acidic solutions, a slightly reduced lifetime can be noted, i.e. $1.62 \pm 0.02 \mathrm{~ns}$ for $\mathrm{pH} 1$. Considerably greater variability is observed in the case of the fractional contribution of the components described. At $\mathrm{pH} 7$, the longer-lifetime component is clearly predominant, as its fractional contribution reaches a value of $97 \%$. In turn, the fractional contribution declines at both the lower and the higher $\mathrm{pH}$ values. In the case of acidic solutions, its fractional contribution drops to $8 \%$ (at $\mathrm{pH} 1$ ), and the greatest change is noted between $\mathrm{pH} 4$ and 3. In alkaline solutions, the lowest fractional contribution of the component was detected at $\mathrm{pH} 12(37 \%)$, and the greatest decline was observed between $\mathrm{pH} 11$ and 12. Since the analysis of the fluorescence intensity decay clearly indicates the presence of

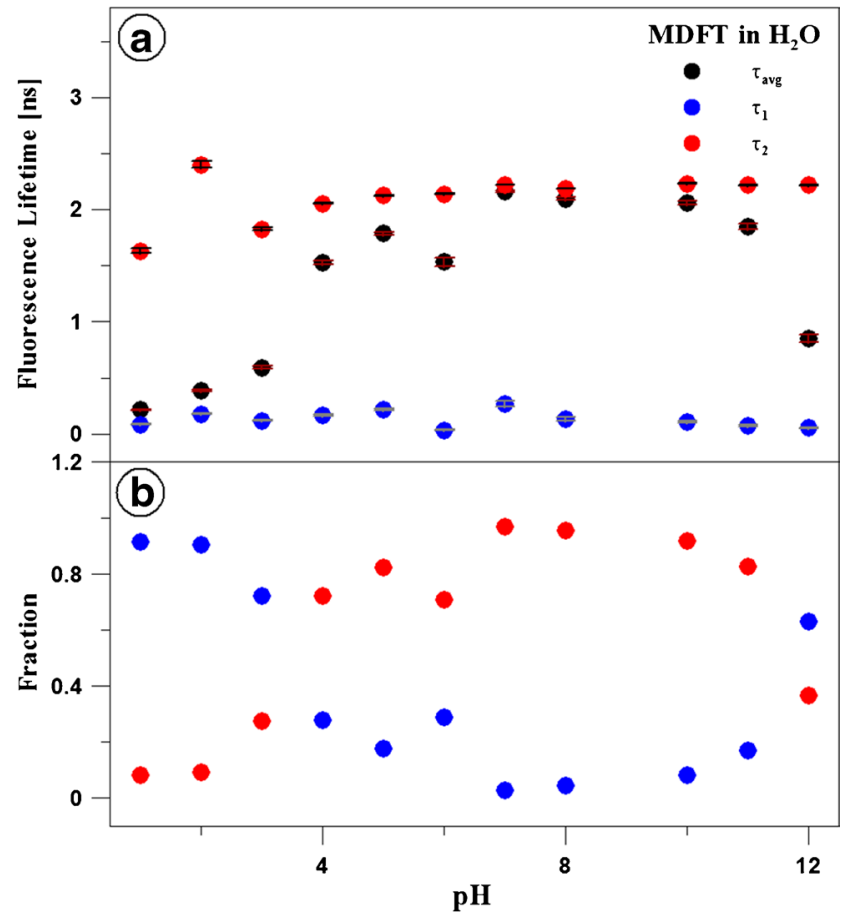

Fig. 6 The effect of $\mathrm{pH}$ on the fluorescence lifetime of MDFT. Panel a presents fluorescence lifetimes of the first $\left(\tau_{1}\right)$ and the second $\left(\tau_{2}\right)$ component of MDFT, together with the mean values observed at various $\mathrm{pH}$. The dependences of the fractional contribution of both components on $\mathrm{pH}$ are presented in panel $\mathbf{b}$. The data analysis was carried out for a two-component model (Eq. 1 for $i=2)$ for data presented in Fig. 6
Fig. 5 The effect of $\mathrm{pH}$ on the fluorescence decay in MDFT. In panel a, the dotted curves show the decay of MDFT fluorescence emission observed with the TCSPC technique in water at a specified $\mathrm{pH}$ value, and the solid lines are double exponential fits. Panel b shows the plots of residuals (determined for the data in panel a). The excitation pulse profile, set up at 372 , is shown by the black dotted curve

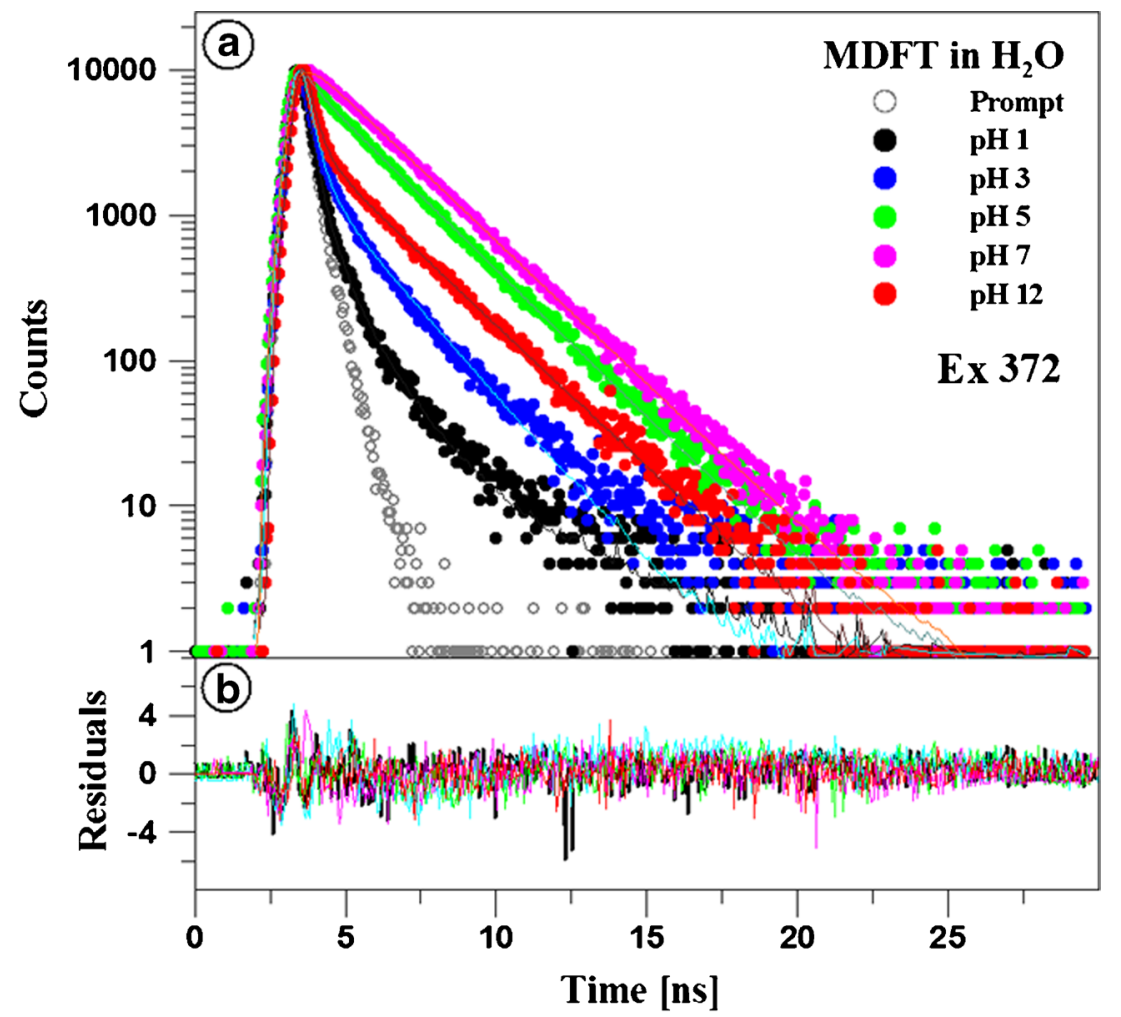



of MDFT in $\mathrm{H}_{2} \mathrm{O}$ in relation to changes in $\mathrm{pH}$
Table 1 Fluorescence lifetimes

\begin{tabular}{ll}
\hline \multicolumn{2}{l}{ MDFT in aqueous solution } \\
\hline $\mathrm{pH}$ & $\tau \pm \Delta \tau$ \\
\hline 1.0 & $0.21 \pm 0.01$ \\
2.01 & $0.39 \pm 0.01$ \\
3.0 & $0.59 \pm 0.01$ \\
4.0 & $1.53 \pm 0.02$ \\
5.01 & $1.79 \pm 0.01$ \\
6.03 & $1.53 \pm 0.04$ \\
7.01 & $2.16 \pm 0.01$ \\
8.06 & $2.10 \pm 0.01$ \\
9.0 & $2.10 \pm 0.01$ \\
10 & $2.06 \pm 0.02$ \\
11.02 & $1.85 \pm 0.02$ \\
12 & $0.85 \pm 0.03$ \\
\hline
\end{tabular}

two components with substantially different lifetimes, these components can be identified with the different fluorophore forms. In this interpretation, the contribution of the observed components (fractal contribution) monitors the transition of the equilibrium between these forms together with changes in the solvent $\mathrm{pH}$. This change is most pronounced in a $\mathrm{pH}$ range corresponding to the first $\mathrm{pK}$ of the analysed compound; therefore, a short lifetime can be regarded characteristic for the protonated/positively ionised form, while a shorter lifetime is typical of the enol form. Another change in the contribution of the fractions is evident in a $\mathrm{pH}$ range close to the second $\mathrm{pK}$, which indicates that the shorter lifetime is characteristic for the deprotonated/negatively ionised MDFT form. Literature often presents analysis based on the value of the mean fluorescence lifetime; therefore, based on these components of fluorescence lifetimes and their fractal contribution, the mean fluorescence lifetimes specific to the different $\mathrm{pH}$ values were determined using Eq. (3). Given the low variability of the values of the fluorescence lifetime components, the relationship is highly similar in its course to the distribution of the contribution of the longer-lifetime component. Importantly, in a pH range in which single fluorescence is observed in the emission spectra, the lifetimes
Fig. 7 Panel a RLS (Resonance Light Scattering) spectra for MDFT obtained in the aqueous solution for the different $\mathrm{pH}$ values. The figure presents $\mathrm{pH}$ $1,3,7,8$, and 10 , respectively. The inset in Panel a presents the ratio of the RLS signal intensity at a wavelength of $400 \mathrm{~nm}$ accompanying $\mathrm{pH}$ changes in the solution. Panel b RLS spectra for MDFT obtained in the aqueous solution at $\mathrm{pH} 3$ and different temperatures (shown: temperature rise; not shown: temperature fall). The inset in Panel $\mathbf{b}$ presents the ratio of the RLS signal intensity at a wavelength of $400 \mathrm{~nm}$ accompanying the temperature fluctuations

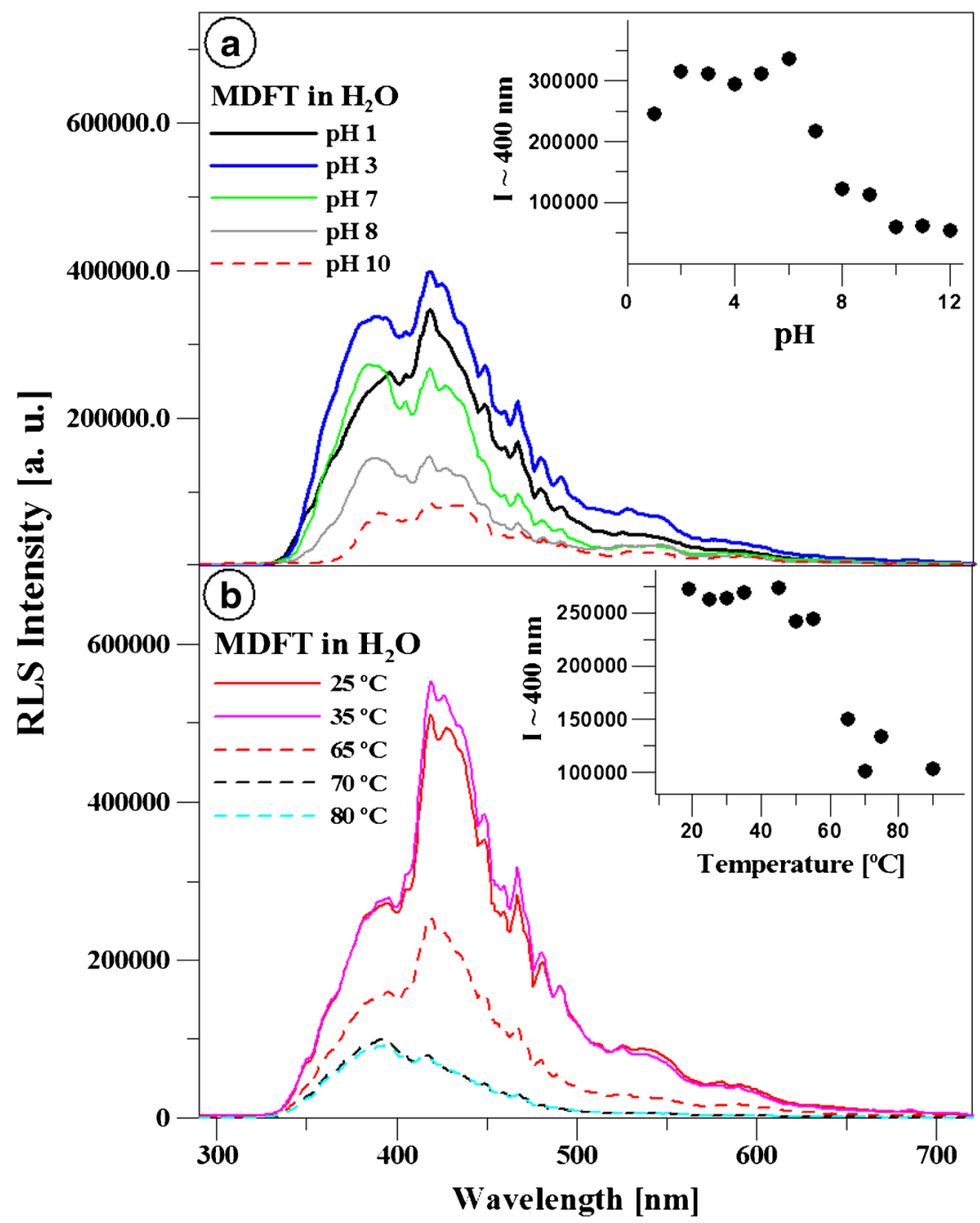


are substantially reduced to approx. $0.45 \mathrm{~ns}$. In contrast, in the region exhibiting longwave fluorescence, the mean fluorescence lifetime increases considerably up to ca. $1.3 \mathrm{~ns}$. The effect of the lengthening of the fluorescence lifetime in the case of molecules in which similar fluorescence phenomena are observed is characteristic for excimer interactions [57], in contrast to processes induced by the aggregation (dimerisation) phenomenon, which is usually characterised by clear reduction [77] or decay of the lifetime.

\section{RLS Study}

In order to investigate the impact of aggregation on the presented fluorescence effects, RLS spectra for MDFT were obtained in water at fluctuations in temperature and $\mathrm{pH}$ of the environment. Panel a in Fig. 7 presents RLS (Resonance Light Scattering, $\Delta \lambda=0$ ) spectra for MDFT generated in the aqueous solution at varying $\mathrm{pH}$ values. Panel $\mathrm{b}$ shows selected RLS spectra for MDFT obtained in the aqueous solution at $\mathrm{pH}$ 2.5 and temperature fluctuations. As indicated in e.g. Pasternak's and Parkash's investigations, the presence of the RLS bands should be attributed to chromophore aggregation of the components contained in the solution $[67,78]$. As can be seen, RLS bands with greater or lesser intensity are present in water at different temperature and $\mathrm{pH}$ values. It is evident that the increase in $\mathrm{pH}$ is accompanied by a decline in the RLS signal. Panel a in the inset in Fig. 7 presents a decline in the intensity of the RLS signal accompanying the increase in the $\mathrm{pH}$ value. The RLS signal loses its intensity substantially at a pH value close to 4. In Panel b, a decline in the RLS signal accompanying the temperature rise is clearly visible, and the inset shows a sharp loss of the signal at a temperature of ca. $60{ }^{\circ} \mathrm{C}$. Above this temperature, the two clearly separated fluorescence emissions disappear as well. RLS spectra and their dependence on the environmental $\mathrm{pH}$ and temperature clearly support the correlation of the presented effect with molecular aggregation. The oscillatory structure of the RLS bands indicates many aggregated MDFT structures, which can vary in size. The observed effect is fully reversible in this case (not shown for clarity of the presented results).

\section{Ex-(1-T)}

In subsequent analysis of the MDFT dual fluorescence and the association of the observed effects with the phenomenon of chromophore aggregation in the compound shown in Fig. 8, the MDFT fluorescence excitation spectra obtained in the aqueous solution at $\mathrm{pH} 1$ and 7 (Panels a and c, respectively) were presented for the same samples in comparison with the 1-T spectra ( $\mathrm{T}-$ transmission). In turn, Panels $b$ and d show differential spectra (1-T)-(Ex). The excitation emission was observed at a wavelength of $445 \mathrm{~nm}(\mathrm{pH}$ 1) and $396 \mathrm{~nm}$ (pH 6), respectively. In the case of the fluorescence excitation spectra, in comparison with the 1-T spectra for both samples at $\mathrm{pH} 1$, distinct bands on the long wave side of the spectrum can be observed, which should be associated with the aggregated form of excited MDFT molecules. Panel a shows that the 1-T MDFT spectrum at $\mathrm{pH} 1$ is hypsochromically shifted, whereas a clear bathochromic shift is visible at $\mathrm{pH} 7$ (Panel c). In accordance with the exciton splitting theory, these shifts are related to two types of aggregation: the hypsochromic shift is associated with "card pack" aggregates and the bathochromic shift is attributed to "head to tail" aggregation [79]. In an alkaline environment, in which the compound is monomerised, a substantially lower number of bands from aggregated forms can be observed. Therefore, a conclusion can be drawn that the effect of two separate fluorescence emissions in the MDFT molecule is clearly

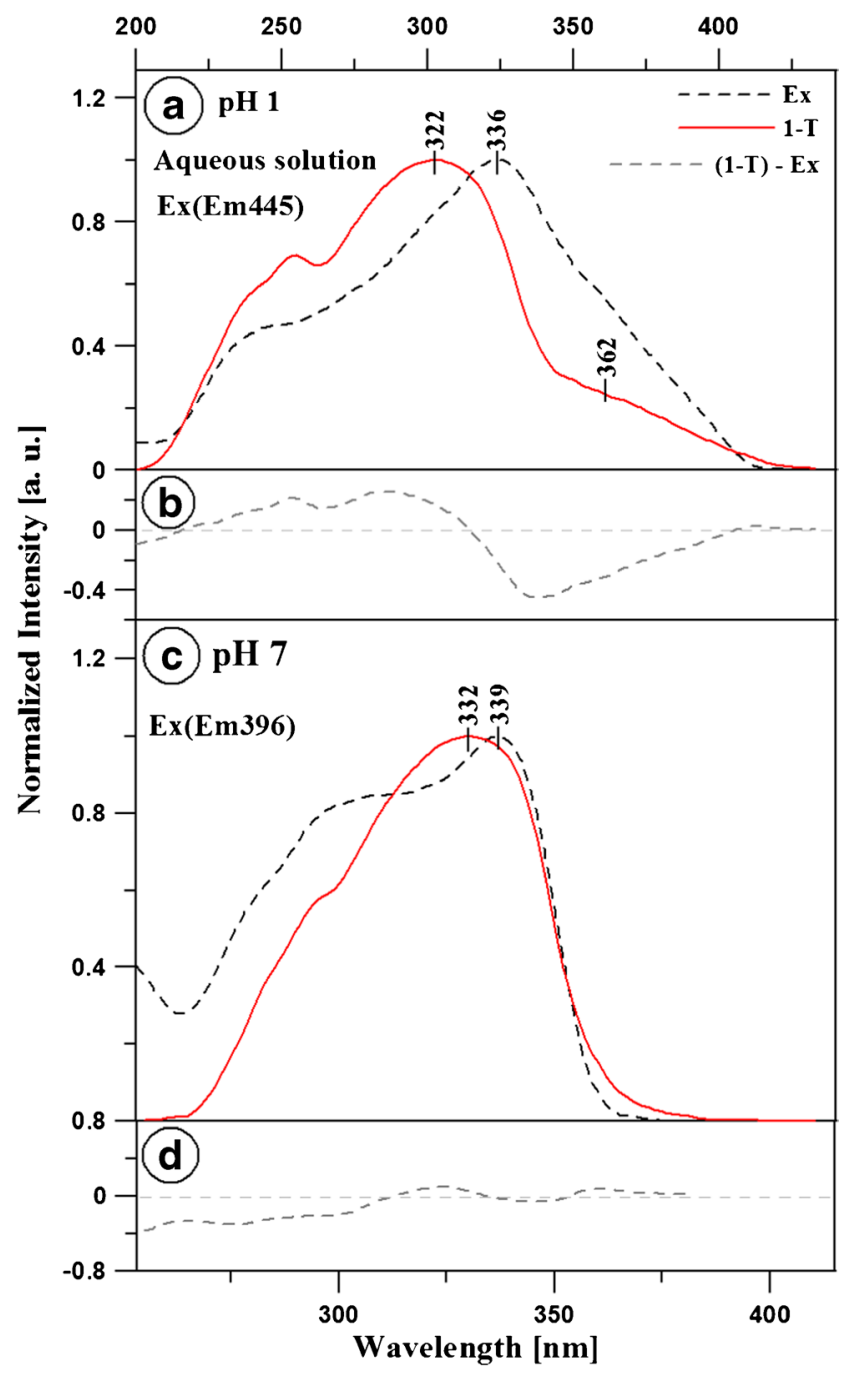

Fig. 8 Panels $\mathbf{a}$ and $\mathbf{b}$ show fluorescence excitation spectra for MDFT in $\mathrm{H}_{2} \mathrm{O}$ at $\mathrm{pH} 1$ (Panel a) and at $\mathrm{pH} 7$ (Panel b) in comparison with the 1-T ( $\mathrm{T}-$ Transmission) spectra. The excitation wavelength at $\mathrm{pH} 1$ is $445 \mathrm{~nm}$ (black lines) and $396 \mathrm{~nm}$ (red lines) 
associated with the effect of molecular aggregation of the compound in the aqueous solution. The RLS analyses which are presented in this article largely confirm this assumption.

\section{Temperature Effects in MDFT Fluorescence Studies}

The next part of the investigations of the fluorescence effects consisted in determination of the effect of temperature on the disaggregation of the analysed systems. Panel a in Fig. 9 presents MDFT fluorescence emission spectra in relation to temperature changes at an excitation wavelength of $397 \mathrm{~nm}$ (dashed lines) and $445 \mathrm{~nm}$ (solid lines). Evidently, the rise in the temperature is accompanied by a decline in the intensity of both fluorescence maxima. Moreover, along with the temperature rise, there is a very distinct shift of the band characteristic for secondary emission $(\operatorname{Em}(\operatorname{Ex} 445))$ from 445 to $414 \mathrm{~nm}$. Panel $\mathrm{b}$ in this figure shows a change in the position of the two fluorescence maxima (for excitation: to 397 and $445 \mathrm{~nm}$ ) depending on temperature changes. The panel clearly shows that the position of the first emission maximum does not change with the rise in the environment temperature, but there is a distinct hypsochromic shift of the long wave fluorescence emission maximum. With the temperature decline, the fluorescence maximum is only slightly shifted to the long waves, and the position of primary emission is virtually unchanged (not shown). In order to check whether the compound underwent degradation, $\mathrm{NaOH}$ and $\mathrm{HCl}$ were added and appropriate fluorescence emission spectra were obtained, which again yielded two separate fluorescence emissions with maxima at 397 and $445 \mathrm{~nm}$ (not shown). In the case of the electron absorption spectra for MDFT in water, depending on the temperature fluctuations, only a slight decline in the absorption maximum was observed (not shown). These results clearly demonstrate the impact of the disaggregation process on the presence of the two fluorescence emission forms, which in turn can be associated with the molecular aggregation of the analysed molecules.

\section{DFT-TDFT Study}

Tables 2 and 3 show the calculation results for the two interaction models: the first model assumes a system of monomeric molecules and the other one assumes a system of aggregated dimeric structures. At the assumption of the monomeric system, a single absorption band with at the energy value of $3.981 \mathrm{eV}(317 \mathrm{~nm})$ and a single fluorescence band at the energy value of $3.159 \mathrm{eV}(393 \mathrm{~nm})$ are predicted. In the dimeric structure model, four states are expected in the interesting range of the absorption spectrum, three of which exhibit substantial intensity. The most important electronic states in terms of comparison with the experimental spectrum include states with vertical transition energies of $3.622 \mathrm{eV}(343 \mathrm{~nm})$ and $3.908 \mathrm{eV}(312 \mathrm{~nm})$, which practically coincide with the maxima in the experiment, see Figs. 3 and 4. The calculation results indicate agreement of the theoretical results with the experimental data in the case of the fluorescence emission spectra. As shown in Table 2, two fluorescence bands located at the energies of $2.806 \mathrm{eV}$ $(442 \mathrm{~nm})$ and $3.307 \mathrm{eV}(375 \mathrm{~nm})$ are noted for the dimer system. The slight discrepancy visible in the case of the $375 \mathrm{~nm}$ state may result from the substantial width of the experimental spectrum. The DFT/TDDFT calculations reproduce quantitatively (see Tables 2 and 3) the main features of absorption and fluorescence spectra, assuming that the moieties responsible for photochemistry are monomeric MDFT in the higher $\mathrm{pH}$ range and protonated aggregates at low $\mathrm{pH}$.

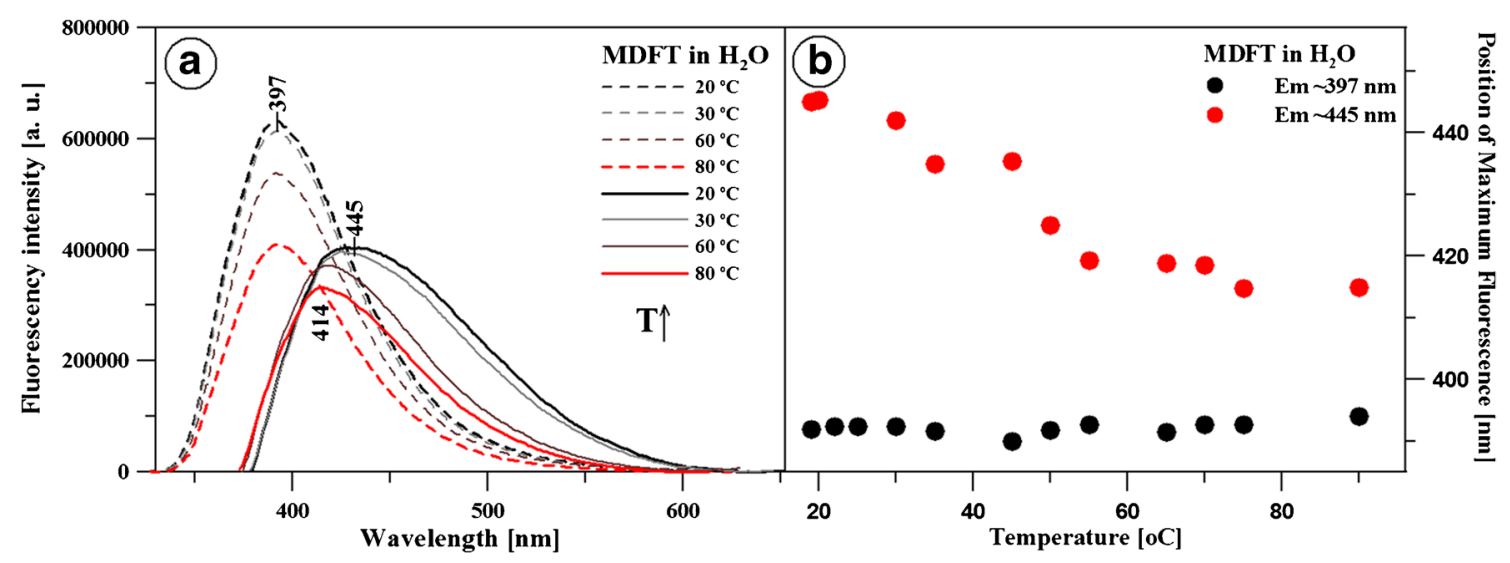

Fig. 9 Panel a presents the fluorescence emission spectrum of MDFT in the aqueous solution at $\mathrm{pH} 3$ together with the change (rise) in the solution temperature in the range from 20 to $80{ }^{\circ} \mathrm{C}$. The excitation wavelength for the spectra is $316 \mathrm{~nm}$ (short-wave emission) and
$360 \mathrm{~nm}$ (long-wave emission). Panel b shows the position of the maxima of the short-wave and long-wave fluorescence emissions together with the rise in the temperature of the aqueous solution from Panel a 
Table 2 Calculated vertical energies of absorption and fluorescence for neutral MDFT monomer and protonated MDFT dimer (DFT/B3LYP in 6-31G** basis set with PCM and LR formalism)

\begin{tabular}{llllllll}
\hline Neutral MDFT monomer & \multicolumn{5}{l}{ Protonated MDFT dimer } \\
\hline Absorption & & & & & \\
Excited state & Energy [eV] & Energy [nm] & Osc. Str & Excited state & Energy [eV] & Energy [nm] & Osc. Str \\
1 & 3,918 & 317 & 0,622 & 1 & 3,622 & 343 & 0,107 \\
& & & 2 & 3,789 & 327 & 0,019 \\
& & & 3 & 3,980 & 312 & 0,505 \\
& & & 4 & 4,096 & 303 & 0,242 \\
Fluorescence & & & & & & \\
Excited state & Energy [eV] & Energy [nm] & Excited state & Energy [eV] & Energy [nm] \\
1 & 3,159 & 393 & 1 & 2,806 & 442 & \\
& & & 3 & 3,307 & 375 & \\
\hline
\end{tabular}

Osc. Str. Oscillator Strength, proportional to intensity
Specifically, the calculations for the protonated dimeric form allowed interpretation of the changes in absorption and the appearance of the new fluorescence phenomena in the low energy region of the spectra as resulting from the existence of the new low-energy dimeric excited state.

\section{Conclusions}

The investigations presented in this article and conducted mainly with fluorescence spectroscopy methods clearly indicate emergence of two separate fluorescence bands in the MDFT emission spectrum in an aqueous solution at a $\mathrm{pH}$ range from 1 to 3.5. The RLS technique has shown that the observed effect largely depends on chromophore aggregation. Furthermore, the substantial shortening of fluorescence lifetimes evidently confirms the accepted model of MDFT molecular aggregation. It has also been shown that the observed phenomenon can be attributed to the combination of two effects, i.e. specific molecule conformation and aggregation effects, which trigger molecular interactions in the analysed system. This hypothesis is confirmed by the TD-DFT calculations, which yield energy values corresponding to the experimental results obtained for the spectral forms when existence of a protonated dimeric system is assumed. The presented investigations can facilitate rapid fluorescence spectroscopy analysis of structural effects in various biologically important model systems.

Table 3 Experimental absorption and fluorescence energies for neutral and protonated MDFT

\begin{tabular}{clllll}
\hline & \multicolumn{2}{l}{ Absorption } & & \multicolumn{2}{l}{ Fluorescence } \\
\cline { 5 - 6 } \cline { 5 - 6 } & Energy [nm] & Energy [eV] & $\begin{array}{l}\text { Wave- } \\
\text { length } \\
{[\mathrm{nm}]}\end{array}$ & Energy [eV] \\
\hline Protonated & 317 & 3,914 & & 389 & 3,189 \\
MDFT & 363 & 3,418 & & 445 & 2,788 \\
Neutral MDFT & 322 & 3,853 & & 396 & 3,133 \\
\hline
\end{tabular}

Acknowledgements The research was supported in part by PL+Grid infrastructure (MM) and partly by the grant from the University of Life Science in Lublin (TKF/MN/5 to AM).

Open Access This article is distributed under the terms of the Creative Commons Attribution 4.0 International License (http://creativecommons.org/licenses/by/4.0/), which permits unrestricted use, distribution, and reproduction in any medium, provided you give appropriate credit to the original author(s) and the source, provide a link to the Creative Commons license, and indicate if changes were made.

\section{References}

1. Haider S, Alam MS, Hamid H (2015) 1,3,4-Thiadiazoles: a potent multi targeted pharmacological scaffold. Eur J Med Chem 92:156-177

2. Tiwari SV, Siddiqui S, Seijas JA, Vazquez-Tato MP, Sarkate AP, Lokwani DK, Nikalje APG (2017) Microwave-assisted facile synthesis, anticancer evaluation and docking study of $\mathrm{N}-((5-$ (substituted methylene amino)-1, 3, 4-thiadiazol-2-yl) methyl) benzamide derivatives. Molecules 22:995

3. Nadeem Siddiqui PA, Waquar Ahsan SN, Pandeya M, Shamsher Alam (2009) Thiadiazoles: progress report on biological activities. JOCPR 1:19-30

4. Megally Abdo NY, Kamel MM (2015) Synthesis and anticancer evaluation of 1,3,4-oxadiazoles, 1,3,4-thiadiazoles, 1,2,4-triazoles and Mannich bases. Chem Pharm Bull (Tokyo) 63:369-376

5. Kumar D, Maruthi Kumar N, Chang KH, Shah K (2010) Synthesis and anticancer activity of 5-(3-indolyl)-1,3,4-thiadiazoles. Eur J Med Chem 45:4664-4668

6. Chabner BA, Roberts TG (2005) Timeline-chemotherapy and the war on cancer. Nat Rev Cancer 5:65-72

7. Aliabadi A, Eghbalian E, Kiani A (2013) Synthesis and evaluation of the cytotoxicity of a series of 1,3,4-thiadiazole based compounds as anticancer agents. IJBMS 16:1133-1138

8. Li Y, Geng J, Liu Y, Yu S, Zhao G (2013) Thiadiazole-a promising structure in medicinal chemistry. ChemMedChem 8:27-41

9. Dawood KM, Gomha SM (2015) Synthesis and anti-cancer activity of 1,3,4-thiadiazole and 1,3-thiazole derivatives having 1,3,4-oxadiazole moiety. J Heterocycl Chem 52:1400-1405

10. Matysiak J, Nasulewicz A, Pelczynska M, Switalska M, Jaroszewicz I, Opolski A (2006) Synthesis and antiproliferative activity 
of some 5-substituted 2-(2,4-dihydroxyphenyl)-1,3,4-thiadiazoles. Eur J Med Chem 41:475-482

11. Cressier D, Prouillac C, Hernandez P, Amourette C, Diserbo M, Lion C, Rima G (2009) Synthesis, antioxidant properties and radioprotective effects of new benzothiazoles and thiadiazoles. Bioorg Med Chem 17:5275-5284

12. Matwijczuk A, Gorecki A, Kaminski D, Mysliwa-Kurdziel B, Fiedor L, Niewiadomy A, Karwasz GP, Gagos M (2015) Influence of solvent polarizability on the keto-enol equilibrium in 4-[5-(naphthalen-1-ylmethyl)-1,3,4-thiadiazol-2-yl]benzene-1,3-diol. J Fluoresc 25:1867-1874

13. Gagos M, Matwijczuk A, Kaminski D, Niewiadomy A, Kowalski R, Karwasz GP (2011) Spectroscopic studies of intramolecular proton transfer in 2-(4-fluorophenylamino)-5-(2,4dihydroxybenzeno)-1,3,4-thiadiazole. J Fluoresc 21:1-10

14. Matwijczuk A, Karcz D, Walkowiak R, Niewiadomy A, Wybraniec S, Karwasz G, Gagos M (2016) Keto-enol tautomerism of 2-(4-fluorophenyl)-5-(2, 4-dihydroxyphenyl)-1, 3, 4-thiadiazole. Spectroscopic studies. Przem Chem 95:1894-1898

15. Matwijczuk A, Karcz D, Walkowiak R, Furso J, Gładyszewska B, Wybraniec S, Niewiadomy A, Karwasz GP, Gagoś M (2017) Effect of solvent polarizability on the keto/enol equilibrium of selected bioactive molecules from the 1, 3, 4-thiadiazole group with a 2, 4-hydroxyphenyl function. J Phys Chem A 121:1402-1411

16. Hoser AA, Kaminski DM, Matwijczuk A, Niewiadomy A, Gagos M, Wozniak K (2013) On polymorphism of 2-(4-fluorophenylamino)-5-(2,4-dihydroxybenzeno)-1,3,4-thiadiazole (FABT) DMSO solvates. Crystengcomm 15:1978-1988

17. Kaminski DM, Hoser AA, Gagos M, Matwijczuk A, Arczewska M, Niewiadomy A, Wozniak K (2010) Solvatomorphism of 2-(4-Fluorophenylamino)-5-(2,4-dihydroxybenzeno)-1,3,4-thiadiazole chloride. Cryst Growth Des 10:3480-3488

18. Kaminski DM, Matwijczuk A, Pociecha D, Gorecka E, Niewiadomy A, Dmowska M, Gagos M (2012) Effect of 2-(4-fluorophenylamino)-5-(2,4-dihydroxyphenyl)-1,3,4-thiadiazole on the molecular organisation and structural properties of the DPPC lipid multibilayers. Biochim Biophys Acta 1818:2850-2859

19. Kluczyk D, Matwijczuk A, Górecki A, Karpińska MM, Szymanek M, Niewiadomy A, Gagoś M (2016) Molecular organization of dipalmitoylphosphatidylcholine bilayers containing bioactive compounds 4-(5-heptyl-1, 3, 4-thiadiazol-2-yl) benzene-1, 3-diol and 4-(5-methyl-1, 3, 4-thiadiazol-2-yl) benzene-1, 3-diols. J Phys Chem B 120:12047-12063

20. Karcz D, Matwijczuk A, Boroń B, Creaven B, Fiedor L, Niewiadomy A, Gagoś M (2017) Isolation and spectroscopic characterization of $\mathrm{Zn}$ (II), Cu (II), and Pd (II) complexes of 1, 3, 4-thiadiazole-derived ligand. J Mol Struct 1128:44-50

21. Matwijczuk A, Kaminski D, Gorecki A, Ludwiczuk A, Niewiadomy A, Mackowski S, Gagos M (2015) Spectroscopic studies of dual fluorescence in 2-((4-fluorophenyl)amino)5-(2,4-dihydroxybenzeno)-1,3,4-thiadiazole. J Phys Chem A 119:10791-10805

22. Matwijczuk A, Kluczyk D, Górecki A, Niewiadomy A, Gagos M (2016) Solvent effects on molecular aggregation in 4-(5-heptyl-1, 3, 4-thiadiazol-2-yl) benzene-1, 3-diol and 4-(5-methyl-1, 3, 4-thiadiazol-2-yl) benzene-1, 3-diol. J Phys Chem B 120:7958-7969

23. Matwijczuk A, Kluczyk D, Górecki A, Niewiadomy A, Gagoś M (2017) Spectroscopic studies of fluorescence effects in bioactive 4-(5-heptyl-1, 3, 4-thiadiazol-2-yl) benzene-1, 3-diol and 4-(5-methyl-1, 3, 4-thiadiazol-2-yl) benzene-1, 3-diol molecules Induced by $\mathrm{pH}$ changes in aqueous solutions. J Fluoresc $1-12$

24. Mishina S, Takayanagi M, Nakata M, Otsuki J, Araki K (2001) Dual fluorescence of 4-dimethylaminopyridine and its derivatives - effects of methyl substitution at the pyridine ring. JPPA 141:153-158

25. Patil VS, Padalkar VS, Tathe AB, Gupta VD, Sekar N (2013) Synthesis, photo-physical and DFT studies of ESIPT inspired novel 2-(2',4'-dihydroxyphenyl) benzimidazole, benzoxazole and benzothiazole. J Fluoresc 23:1019-1029

26. Zhou PW, Hoffmann MR, Han KL, He GZ (2015) New insights into the dual fluorescence of methyl salicylate: effects of intermolecular hydrogen bonding and solvation. J Phys Chem B 119:2125-2131

27. Matwijczuk A, Karcz D, Kluczyk D, Matwijczuk A, Gładyszewska B, Niewiadomy A, Gagoś M (2017) Temperaturowe efekty podwójnej fluorescencji 4-(5-heptylo-1, 3, 4-tiadiazol-2-ilo) benzeno-1, 3-diolu (C7). Przem Chem

28. Matwijczuk A, Matwijczuk A, Karcz D, Wybraniec S, Kluczyk D, Gagoś M, Niewiadomy A (2017) Spectroscopic studies of dual fluorescence effects in a selected 1,3,4-thiadiazole derivative in organic solvents and aqueous solutions. Technical Transactions 3:47-61

29. Yang Y, Li D, Li C, Liu Y, Jiang K (2017) Hydrogen bond strengthening induces fluorescence quenching of PRODAN derivative by turning on twisted intramolecular charge transfer. Spectrochim Acta A 187:68-74

30. Li Y, Chu T-S (2017) A DFT/TDDFT Study on the sensing mechanism of a fluorescent probe for hydrogen sulfide: excited state intramolecular proton transfer coupled twisted intramolecular charge transfer. J Phys Chem A 121:5245-5256

31. Ishi-i T, Moriyama Y (2017) Bis (thiadiazole) quinoxaline-and bis (thiadiazole) phenanthroquinoxaline-based donor-acceptor type dyes showing simultaneous emission efficiency and color changes from molecular aggregation and twisted intramolecular charge transfer. Tetrahedron 73:1157-1164

32. Tanaka M, Muraoka S, Matsui Y, Ohta E, Ogaki T, Mizuno K, Ikeda H (2017) Cooperative effects of o-and m-methyl groups on the intramolecular charge-transfer emission properties of dibenzoylmethanatoboron difluorides. Photochem Photobiol Sci

33. Saha SK, Deb J, Sarkar U, Paul MK (2017) Hockey-stick-shaped mesogens based on 1, 3, 4-thiadiazole: synthesis, mesomorphism, photophysical and DFT studies. Liq Cryst 1-19

34. Yang JS, Lin CK, Lahoti AM, Tseng CK, Liu YH, Lee GH, Peng SM (2009) Effect of ground-state twisting on the trans --> cis photoisomerization and TICT state formation of aminostilbenes. J Phys Chem A 113:4868-4877

35. Broquier M, Soorkia S, Dedonder-Lardeux C, Jouvet C, Theulé $P$, Grégoire G (2016) Twisted intramolecular charge transfer in protonated amino pyridine. J Phys Chem A 120:3797-3809

36. Lee S-K, Kim JO, Shimizu D, Osuka A, Kim D (2016) Effect of bulky meso-substituents on photoinduced twisted intramolecular charge transfer processes in meso-diarylamino subporphyrins. JPP 20:663-669

37. Lim C-H, Ryan MD, McCarthy BG, Theriot JC, Sartor SM, Damrauer NH, Musgrave CB, Miyake GM (2017) Intramolecular charge transfer and ion pairing in N, N-diaryl dihydrophenazine photoredox catalysts for efficient organocatalyzed atom transfer radical polymerization. J Am Chem Soc 139:348-355

38. Zachariasse KA, Demeter A, Druzhinin SI (2017) Absence of intramolecular charge transfer with 4-fluoro-N, N-dimethylaniline (DMA4F), contrary to an experimental report supported by computations. J Phys Chem A 121:1223-1232

39. Ahmad M, Platonova I, Battisti A, Minei P, Brancato G, Pucci A (2017) Highly selective vapochromic fluorescence of polycarbonate films doped with an ICT-based solvatochromic probe. J Polym Sci Part B 1-10

40. Bohnwagner MV, Burghardt I, Dreuw A (2016) Solvent polarity tunes the barrier height for twisted intramolecular charge transfer in N-Pyrrolobenzonitrile (PBN). J Phys Chem A 120:14-27 
41. Cao C, Liu X, Qiao Q, Zhao M, Yin W, Mao D, Zhang H, Xu $\mathrm{Z}$ (2014) A twisted-intramolecular-charge-transfer (TICT) based ratiometric fluorescent thermometer with a mega-stokes shift and a positive temperature coefficient. Chem Commun (Camb) 50:15811-15814

42. Deshmukh MS, Sekar N (2014) Novel twisted intramolecular charge transfer (TICT) extended fluorescent styryl derivatives containing quinoline electron releasing moiety. J Fluoresc 24:1811-1825

43. Scuppa S, Orian L, Donoli A, Santi S, Meneghetti M (2011) AntiKasha's rule fluorescence emission in (2-ferrocenyl)indene generated by a twisted intramolecular charge-transfer (TICT) process. J Phys Chem A 115:8344-8349

44. Krishnamoorthy G, Dogra SK (1999) Twisted intramolecular charge transfer emission of 2-(4'-N,N-dimethylaminophenyl) benzimidazole in Micelles. J Colloid Interface Sci 213:53-61

45. Sasaki S, Drummen GP, Konishi G-I (2016) Recent advances in twisted intramolecular charge transfer (TICT) fluorescence and related phenomena in materials chemistry. J Mater Chem C 4:2731-2743

46. Liu X, Qiao Q, Tian W, Liu W, Chen J, Lang MJ, Xu Z (2016) Aziridinyl fluorophores demonstrate bright fluorescence and superior photostability by effectively inhibiting twisted intramolecular charge transfer. JACS 138:6960-6963

47. Naito H, Nishino K, Morisaki Y, Tanaka K, Chujo Y (2017) Solid-state emission of the anthracene-o-carborane dyad from the twisted-intramolecular charge transfer in the crystalline state. Angew Chem Int Ed 56:254-259

48. Lu H, Zheng Y, Zhao X, Wang L, Ma S, Han X, Xu B, Tian W, Gao H (2016) Highly efficient far red/near-infrared solid fluorophores: aggregation-induced emission, intramolecular charge transfer, twisted molecular conformation, and bioimaging applications. Angew Chem Int Ed 55:155-159

49. Teran NB, He GS, Baev A, Shi Y, Swihart MT, Prasad PN, Marks TJ, Reynolds JR (2016) Twisted thiophene-based chromophores with enhanced intramolecular charge transfer for cooperative amplification of third-order optical nonlinearity. JACS 138:6975-6984

50. Gilabert A, Fajarí L, Sirés I, Reig M, Brillas E, Velasco D, Anglada JM, Juliá L (2017) Twisted intramolecular charge transfer in a carbazole-based chromophore: the stable [(4-N-carbazolyl)-2, 3, 5, 6-tetrachlorophenyl] bis (2, 3, 5, 6-tetrachlorophenyl) methyl radical. New J Chem

51. Hubin PO, Laurent AD, Vercauteren DP, Jacquemin D (2014) Investigation of ESIPT in a panel of chromophores presenting $\mathrm{N}-\mathrm{HN}$ intramolecular hydrogen bonds. Phys Chem Chem Phys 16:25288-25295

52. Deshmukh MS, Sekar N (2015) Photophysical properties of ESIPT inspired fluorescent 2-(2-hydroxyphenyl)-6-methylimidazo[4,5-f] isoindole-5,7 $(1 \mathrm{H}, 6 \mathrm{H})$-dione and its derivative: experimental and DFT based approach. Spectrochim Acta A Mol Biomol Spectrosc 135:457-465

53. Santos FS, Ramasamy E, Ramamurthy V, Rodembusch FS (2014) Excited state chemistry of flavone derivatives in a confined medium: ESIPT emission in aqueous media. Photochem Photobiol Sci 13:992-996

54. Marri E, Galiazzo G, Mazzucato U, Spalletti A (2000) Effect of solvent polarizability on dual fluorescence of EE-1-phenyl,4-(1 '-pyrenyl)-1,3-butadiene. Chem Phys 260:383-390

55. Li H, Niu L, Xu X, Zhang S, Gao F (2011) A comprehensive therotical investigation of intramolecular proton transfer in the excited states for some newly-designed diphenylethylene derivatives bearing 2-(2-hydroxy-phenyl)-benzotriazole part. J Fluoresc 21:1721-1728
56. Ding G, Lu Y, Qin X, Su J, Zhang S, Li H, Luo Z, Chen L, Gao $F$ (2017) New organic conjugated dye nano-aggregates exhibiting naked-eye fluorescence color switching. Dyes Pigments 139:19-32

57. Graceffa P, Lehrer SS (1980) The excimer fluorescence of pyrenelabeled tropomyosin. A probe of conformational dynamics. J Biol Chem 255:11296-11300

58. Qomi HR, Habibi A, Shahcheragh SM (2017) Synthesis and fluorescence studies of nine 1, 5-benzodiazepine-2, 4-dione derivatives: dual emission and excimer fluorescence. Spectrochim Acta Mol Biomol Spectrose 174:164-170

59. Pirouz S, Duhamel J, Jiang S, Duggal A (2017) Using pyrene excimer fluorescence to probe the interactions between viscosity index improvers and waxes present in automotive oil. Macromolecules 50:2467-2476

60. Casier R, Gauthier M, Duhamel J (2017) Using pyrene excimer fluorescence to probe polymer diffusion in latex films. Macromolecules 50:1635-1644

61. Liu H, Cong D, Li B, Ye L, Ge Y, Tang X, Shen Y, Wen Y, Wang J, Zhou C (2017) Discrete dimeric anthracene stackings in solids with enhanced excimer fluorescence. Cryst Growth Des

62. Deria P, Yu J, Smith T, Balaraman RP (2017) Ground-state versus excited-state interchromophoric interaction: topology dependent excimer contribution in metal-organic framework photophysics. JACS 139:5973-5983

63. Kraskouskaya D, Cabral A, Fong R, Bancerz M, Toutah K, Rosa D, Gardiner J, de Araujo E, Duodu E, Armstrong D (2017) Characterization and application studies of ProxyPhos, a chemosensor for the detection of proximally phosphorylated peptides and proteins in aqueous solutions. Analyst

64. Krasheninina O, Lomzov A, Fishman V, Novopashina D, Venyaminova A (2017) Rational design and studies of excimer forming novel dual probes to target RNA. Bioorg Med Chem 25:2244-2250

65. Brancato G, Signore G, Neyroz P, Polli D, Cerullo G, Abbandonato G, Nucara L, Barone V, Beltram F, Bizzarri R (2015) Dual fluorescence through Kasha's rule breaking: an unconventional Photomechanism for intracellular probe design. J Phys Chem B 119:6144-6154

66. Kaminski A, Matwijczuk A, Hoser AA, Niewiadomy A, Woźniak K, Gagoś M (2011) Characteristics of 2-methylamino-5-(2.4 dihydroxybenzene)-1,3,4 -thiadiazole chloride. In: Science and industry. UMCS - Maria Curie-Skłodowska University, Lublin

67. Parkash J, Robblee JH, Agnew J, Gibbs E, Collings P, Pasternack RF, de Paula JC (1998) Depolarized resonance light scattering by porphyrin and chlorophyll a aggregates. Biophys J 74:2089-2099

68. Frisch GW, Trucks HB, Schlegel GE, Scuseria MA, Robb JR, Cheeseman G, Scalmani V, Barone B, Mennucci GA, Petersson H, Nakatsuji M, Caricato X, Li HP, Hratchian AF, Izmaylov J, Bloino G, Zheng JL, Sonnenberg M, Hada M, Ehara K, Toyota R, Fukuda J, Hasegawa M, Ishida T, Nakajima Y, Honda O, Kitao H, Nakai T, Vreven JA, Montgomery JE Jr, Peralta F, Ogliaro M, Bearpark JJ, Heyd E, Brothers KN, Kudin VN, Staroverov R, Kobayashi J, Normand K, Raghavachari A, Rendell JC, Burant SS, Iyengar J, Tomasi M, Cossi N, Rega JM, Millam M, Klene JE, Knox JB, Cross V, Bakken C, Adamo J, Jaramillo R, Gomperts RE, Stratmann O, Yazyev AJ, Austin R, Cammi C, Pomelli JW, Ochterski RL, Martin K, Morokuma VG, Zakrzewski GA, Voth P, Salvador JJ, Dannenberg S, Dapprich, Daniels AD, Farkas Ö, Foresman JB, Ortiz JV, Cioslowski J, Fox DJ (2009) Gaussian 09 RD MJ. Gaussian Inc., Wallingford

69. Becke AD (1993) Density-functional thermochemistry. III. The role of exact exchange. J Chem Phys 98:5648-5652 
70. Krishnan R, Binkley JS, Seeger R, Pople JA (1980) Self-consistent molecular orbital methods. XX. A basis set for correlated wave functions. Chem Phys 72

71. Grimme S, Ehrlich S, Goerigk L (2011) Effect of the damping function in dispersion corrected density functional theory. J Comp Chem 32:1456-1465

72. Tomasi J, Mennucci B, Cammi R (2005) Quantum mechanical continuum solvation models. Chem Rev 105:2999-3093

73. Casida ME (1996) Time-dependent density functional response theory of molecular systems: theory, computational methods, and functional. In: Seminario JM (ed) Recent developments and applications of modern density functional theory. Elsevier, Amsterdam, p 391

74. Klimovich VM (1983) [Spectroscopic study of hydration and the dynamic structure of trypsin and some of its lipid-protein and protein-lipid-carbohydrate complexes]. Biofizika 28:24-29

75. Binder H, Gutberlet T, Anikin A, Klose G (1998) Hydration of the dienic lipid dioctadecadienoylphosphatidylcholine in the lamellar phase-an infrared linear dichroism and X-ray study on headgroup orientation, water ordering, and bilayer dimensions. Biophys J $74: 1908-1923$
76. Kasha M, Rawls HR, Ashraf El-Bayoumi M (1965) The exciton model in molecular spectroscopy. Pure Appl Chem 11:371-392

77. Karcz D, Boron B, Matwijczuk A, Furso J, Staron J, Ratuszna A, Fiedor L (2014) Lessons from chlorophylls: modifications of porphyrinoids towards optimized solar energy conversion. Molecules 19:15938-15954

78. Pasternack R, Collings P (1995) Resonance light scattering: a new technique for studying chromophore aggregation. Science 269:935-939

79. Kasha M (2012) Energy transfer mechanisms and the molecular exciton model for molecular aggregates. Radiat Res 178:Av27-Av34 